\title{
Based on FP LDs with split band technique in two-channel fiber optical CATV transport system
}

\author{
Wen-Shing Tsai ${ }^{1,}$, Hong-Yu Dai ${ }^{1}$, and Chung-Yi $\mathrm{Li}^{2}$ \\ ${ }^{1}$ Department of Electrical Engineering, Ming Chi University of Technology, Taipei, 24301 Taiwan \\ ${ }^{2}$ Institute of Electro-Optical Engineering, National Taipei University of Technology, New Taipei City, \\ 10608 Taiwan
}

\begin{abstract}
This study proposes a two-channel fiber optic cable television (CATV) transport system based on Fabry-Perot laser diodes (FP-LDs) with a split band technique. To reduce the interference between channels, we apply the split band technique to two channels with different frequencies by using two converters at each moment. In this two-channel transmission scheme, composite second-order (CSO) and composite triple-beat (CTB) distortions induced by the systems are possibly confined in unused channels and result in good transmission performances. Through a $40 \mathrm{~km}$ standard single-mode fiber transmission, excellent performances of carrier-to-noise ratio ( $\geq 50 \mathrm{~dB})$, CSO ( $\geq 70 \mathrm{~dB})$, and CTB ( $\geq 72 \mathrm{~dB})$ are obtained using the proposed fiber optic CATV transport systems. The proposed systems employing FP-LDs with a split band technique are also simpler and more cost effective than conventional externally modulated systems.
\end{abstract}

\section{Introduction}

For fiber optical CATV transport systems, the maximum fiber link using cascaded erbium-doped fiber amplifiers (EDFAs) is limited by RF parameters such as carrier to noise ratio (CNR), composite second-order (CSO), and composite triple beat (CTB) [1, 2]. These parameters can be seriously degraded by stimulated Brillouin scattering (SBS), stimulated Raman scattering (SRS), and fiber dispersion effects in 1550-nm fiber optical CATV transport systems. Several ways have been proposed to solve these problems such as employing an externally modulated transmitter and differential detection through two fiber links [3], using external light injection locking or sideband filtering techniques [4,5], the $\mathrm{CSO}$ and CTB performances can be improved [6-8]. Nevertheless, an expensive externally modulated transmitter as well as sophisticated differential detection, external light injection locking, and sideband filtering techniques are required. And further, it is difficult to obtain good CNR, CSO, and CTB transmission performances owing to full channel loading. In this letter, a structure of directly modulated fiber optical CATV transport system based on Fabry-Perot laser diodes (FP LDs) with split band technique is proposed and experimentally demonstrated. Under such two-channel transmission scheme, CSO and CTB

${ }^{*}$ Corresponding author: wst@mail.mcut.edu.tw 
distortions induced by systems are dramatically reduced. Over a 40-km single-mode fiber (SMF) transmission, excellent performances of CNR ( $\geq 50 \mathrm{~dB}), \mathrm{CSO}(\geq 70 \mathrm{~dB})$, and CTB $(\geq 72 \mathrm{~dB})$ are obtained in the proposed directly modulated fiber optical CATV transport systems. To compare with a conventional externally modulated fiber optical CATV system, the proposed system reveals a prominent merit with simpler and more economic advantages.

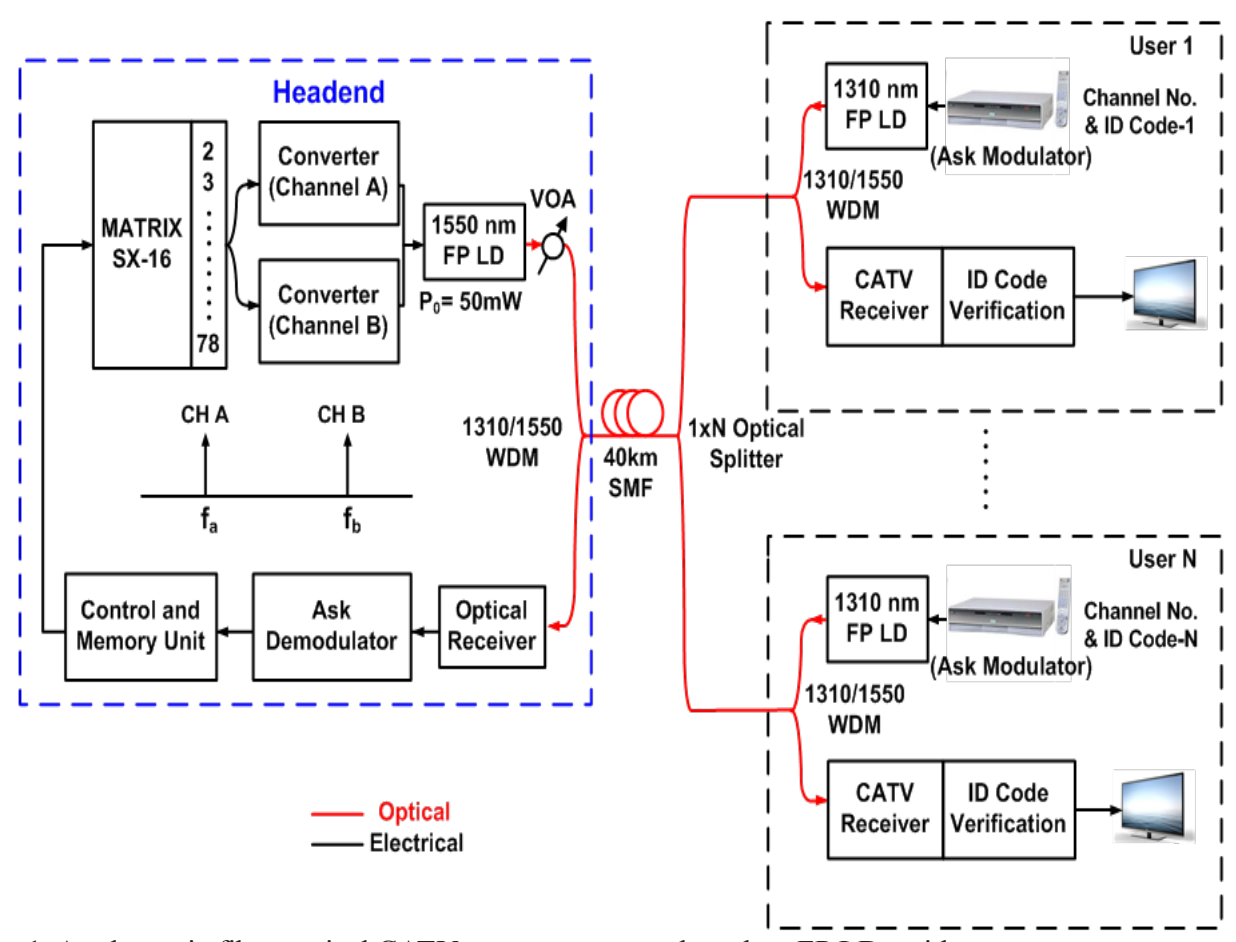

Fig. 1. A schematic fiber optical CATV transport system based on FP LDs with two-channel transmission.

The schematic system of fiber optical CATV transport system based on FP LDs with split band technique is shown in Fig. 1. This system can be used by $\mathrm{N}$ users simultaneously. Each user can uplink the identification (ID) code of desired channel to the headend through direct modulating the $1310 \mathrm{~nm}$ FP LD via a channel selector such as set-top box, station selector etc. The headend picks the selected channel through the ID code uploaded by user and downloads to user via direct modulating the $1550 \mathrm{~nm}$ FP LD. As the user receives the channels transmitted from the headend, an ID code verification will be excuted to verify whether the channel is the user desired. Meanwhile, to avoid the interference of other channels, we choose two channels with different frequencies by using two converters at each moment which avoid the expensive equipment and complex systems that are required by the system of full channel loading [3-9].

\section{Experimental setup}

Fig. 2 presents two different fiber optical CATV transport systems. Fig. 2(a), referred to as system I, shows the conventional 77-channel fully loading externally modulated fiber optical CATV transport system. Fig. 2(b), referred to as system II, shows our proposed 
directly modulated fiber optical CATV transport system with two-channel transmission. System I employs an EDFA to deliver optical signal over a 40-km SMF transmission. System II employs a high power FP LD to transmit optical signal over a 40-km SMF transmission. In system I, the EDFA has an output power of $16 \mathrm{dBm}$ and a noise figure of $4.5 \mathrm{~dB}$ at an input power of $0 \mathrm{dBm}$. For the externally modulated transmitter with an optical modulation index (OMI) of 3.5\%, its SBS-suppression ability is about $+16 \mathrm{dBm}$. Thereby, the optical power launched into the fiber should be kept at $\leq+16 \mathrm{dBm}$ to avoid the degradation induced by the SBS effect. The FP LD used in system II has an operating wavelength of $1550 \mathrm{~nm}$, an operation current of $500 \mathrm{~mA}$, and a relative intensity noise (RIN) of about $-130 \mathrm{~dB} / \mathrm{Hz}$. The OMI per channel of the FP LD transmitter is $4.8 \%$, and the optical output power of the FP LD transmitter is $50 \mathrm{~mW}$.

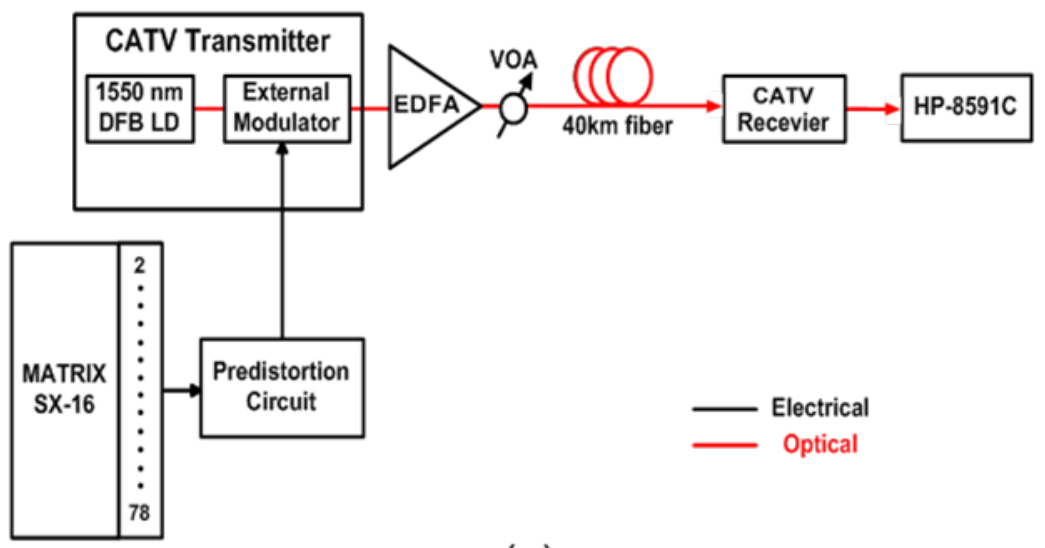

(a)

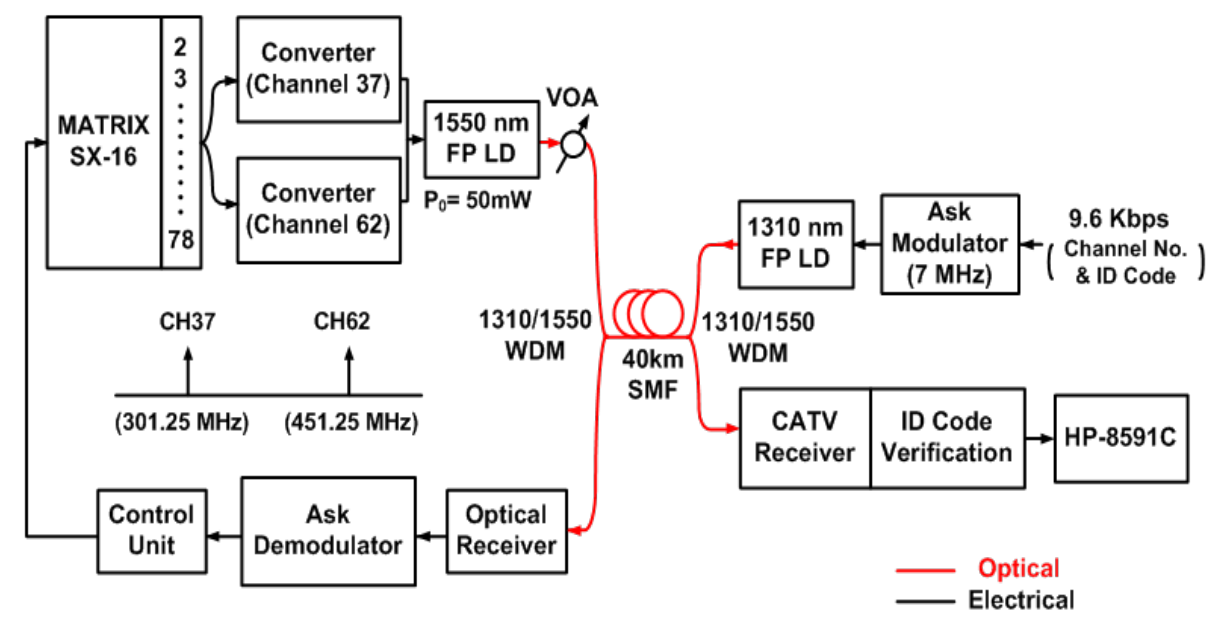

(b)

Fig. 2. (a) System I: Schematic of the conventional 77-channel fully loading externally modulated systems. (b) System II (new proposed): Schematic of the NTSC 77-channel systems based on FP LDs with two-channel transmission.

In system I, as shown in Fig. 2(a), channels 2-78 (55.25-547.25 MHz) generated from a multi-carrier generator (Matrix SX-16) are fed into an external modulator. The input power of the EDFA is kept at $0 \mathrm{dBm}$, the fiber transmission loss is about $0.4 \mathrm{~dB} / \mathrm{km}$, and each EDFA has a 16-dB link budget. Therefore, the optical power amplified by an EDFA has a 
sufficient power budget for transmission over a 40-km SMF link. The variable optical attenuator (VOA) is set after the EDFA, which results in less distortion as the optical power launched into the fiber. Over a 40-km SMF transmission, the optical signal is fed into an optical receiver. The optical input power level of the optical receiver is adjusted as $0 \mathrm{dBm}$, and the RF output level of the optical receiver is kept ab over $30 \mathrm{dBmV}$ per channel. All CATV parameters (CNR, CSO, and CTB) are measured and analyzed using an HP-8591C CATV analyzer after a 40-km SMF transmission.

In system II, as shown in Fig. 2(b), channels 2-78 are split by a $1 \times 2$ RF splitter, went through two separate converters, recombined the CATV signals using a $2 \times 1 \mathrm{RF}$ combiner, and directly fed into a $1550-\mathrm{nm}$ FP LD transmitter. It should be noted that system I is a uni-directional transmission system, whereas system II is a bi-directional transmission system. The control code $(9.6 \mathrm{Kbps})$ for channel number selection and ID code at the optical node is modulated by an amplitude shift keying (ASK) modulator, and the upstream carrier frequency is located at $7 \mathrm{MHz}$. By using two-way transmission, system II just only transmit two channels to the optical node with two separate converters at the headend. The converters will convert the selected channels into channel 37 and channel 62 with ID code by a control unit. The function of the control unit is to verify the ID code of user and pick out the channel selected by the user. Over a $40-\mathrm{km}$ SMF transport, the optical signal is launched into a CATV receiver with ID code verification for down-link transmission. For optimum performance of the CATV receiver, the optical input power level of the optical receiver is kept at $0 \mathrm{dBm}$, and the $\mathrm{RF}$ output level of the optical receiver is kept above 30 $\mathrm{dBmV}$ per channel. CNR, CSO, and CTB parameters are measured and evaluated using an HP-8591C CATV analyzer over a 40-km SMF link.

\section{Results and discussion}

Figs. 3-5 show the measured CNR, CSO and CTB values under NTSC channel number of systems I and II, as well as the schematic CNR, CSO and CTB definitions. CNR can be expressed as:

$$
C N R=10 \log \left[\frac{\text { Carrier level }}{\text { Noise level }}\right]
$$

It can be seen that the CNR value of system II is lower than that of system I about $3 \mathrm{~dB}$. The CNR performance is given by [10-11]:

$$
\mathrm{CNR}=\left(\mathrm{CNR}_{\mathrm{RIN}}^{-1}+\left(\mathrm{CNR}_{\text {th }}^{-1}+\mathrm{CNR}_{\text {shot }}^{-1}\right)\right)^{-1}
$$




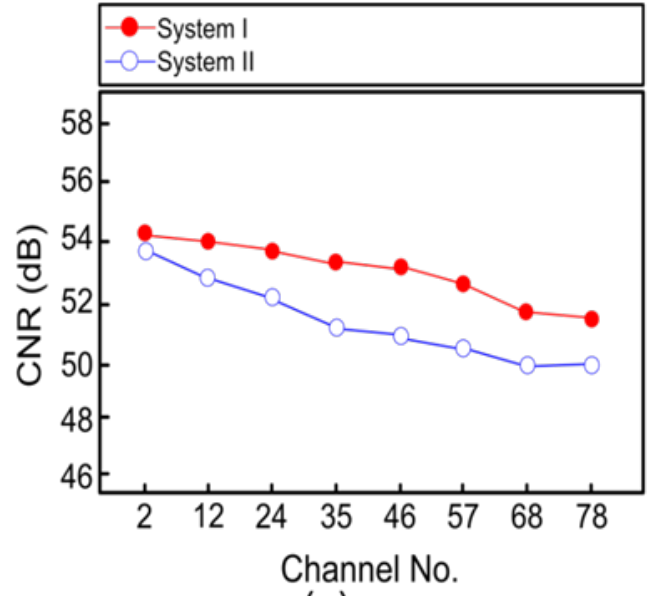

(a)

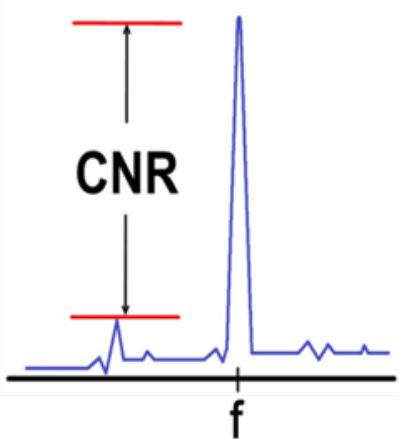

(b)

Fig. 3. (a)The measured CNR value under NTSC channel number of systems I and II, and (b) the schematic CNR definition.

where $\mathrm{CNR}_{\mathrm{RIN}}$ results from the RIN of $\mathrm{LD} ; \mathrm{CNR}_{\text {th }}$ (resulting from thermal noise) and $\mathrm{CNR}_{\text {shot }}$ (resulting from shot noise) are associated with the optical receiver. The CNR value of system II can be improved by using a FP LD with lower RIN value $(\leq-135 \mathrm{~dB} / \mathrm{Hz})$, because higher CNR value can be obtained from a LD with lower RIN value. However, the CNR value of system II is equal to or higher than the threshold value $(\geq 50 \mathrm{~dB})$, indicating the least quality of demand.

By contrast, the CSO and CTB performances of the system II can be significantly improved. CSO and CTB are given by:

$$
\begin{gathered}
C S O=10 \log \left[\frac{(\text { Carrier level })}{(\text { Second order beat distortion level })}\right] \\
C T B=10 \log \left[\frac{\text { Carrier level }}{\text { Triple order beat distortion level }}\right]
\end{gathered}
$$

The CSO and CTB values of the system II are higher than 70 and $72 \mathrm{~dB}$. These improvements can be attributed to the use of two-channel transmission scheme to reduce the CSO and CTB distortions induced by systems. The CSO and CTB distortions can be stated by [12]:

$$
\begin{aligned}
& \mathrm{CSO}=10 \log \left[\frac{\mathrm{mD} \lambda_{\mathrm{c}}^{2} \mathrm{Lf}}{4 \mathrm{c}} \sqrt{16(\Delta \tau)^{2}+\frac{4 \lambda_{\mathrm{c}}^{4} \mathrm{~L}^{2} \pi^{2} \mathrm{f}^{6}}{\mathrm{c}^{2}}}\right]+10 \log \mathrm{N}_{\mathrm{CSO}}+6 \\
& C T B=10 \log \left[\frac{9 m^{2} D^{2} \lambda_{c}^{4} L^{2} f^{2}}{4 c}\left(4(\Delta \tau)^{2}+4 \pi^{2} f\right)\right]+10 \log N_{\text {CTB }}+6
\end{aligned}
$$




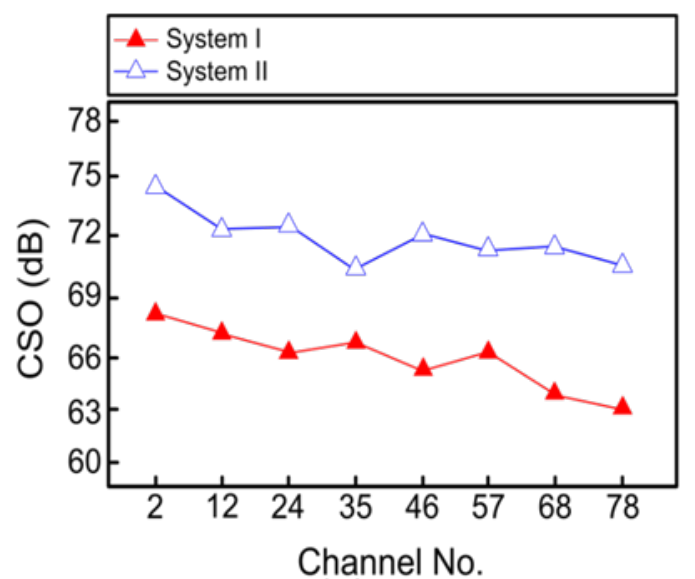

(a)

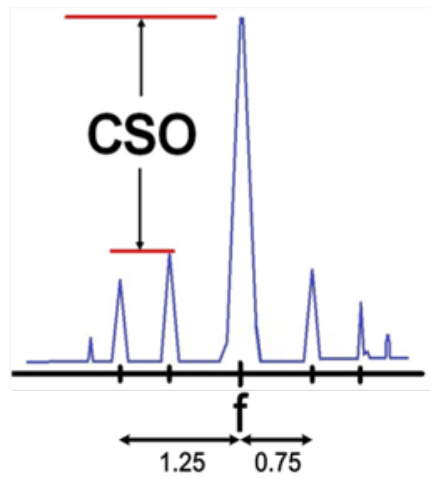

(b)

Fig. 4. (a)The measured CSO value under NTSC channel number of systems I and II, and (b) the schematic CSO definition.

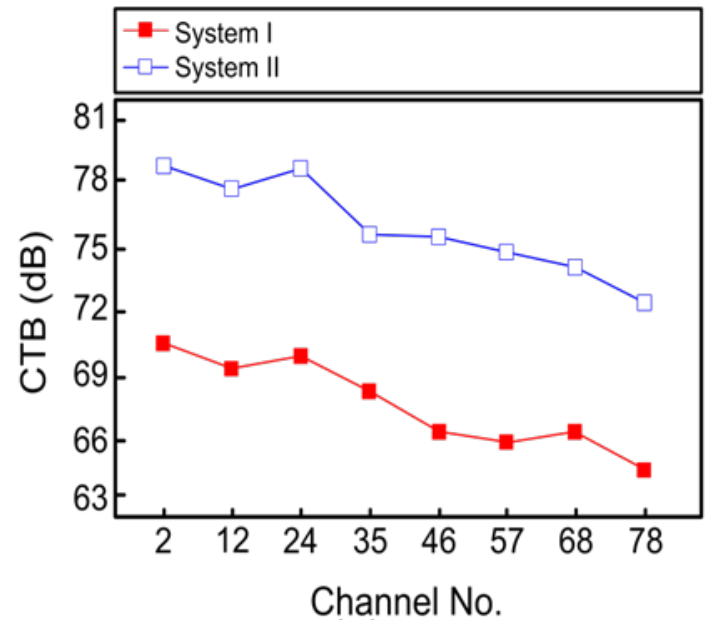

(a)

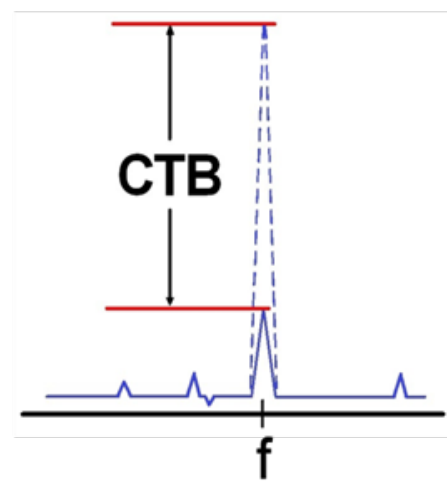

(b)

Fig. 5. (a)The measured CTB value under NTSC channel number of systems I and II, and (b) the schematic CTB definition.

where $\mathrm{m}$ is the OMI, $\mathrm{D}$ is the dispersion coefficient, $\lambda_{c}$ is the optical carrier wavelength, $\mathrm{L}$ is the fiber length, $f$ is the RF frequency, $\Delta \tau$ is the fiber dispersion, NCSO and NCTB are the product counts of CSO and CTB. By using two-channel transmission scheme, a very smaller $\mathrm{N}_{\mathrm{CSO}}$ and $\mathrm{N}_{\mathrm{CTB}}$ can be obtained from just only two channels. Thereby, a major part of CSO and CTB distortions will be automatically deleted in such two-channel transmission scheme. For instance, the carrier frequencies of $\mathrm{CH} 37$ and CH62 are 301.25 and 451.25 MHz, we can derive the second-order intermodulation distortions (IMD2):

$$
\begin{aligned}
& \text { 451.25 MHz (CH62) - 301.25 MHz (CH37) }=150 \mathrm{MHz} \\
& 301.25 \mathrm{MHz}(\mathrm{CH} 37)+451.25 \mathrm{MHz}(\mathrm{CH} 62)=752.5 \mathrm{MHz}
\end{aligned}
$$


The carrier frequencies of CH19 and $\mathrm{CH} 117$ are 151.25 and $751.25 \mathrm{MHz}$, it can be seen that the CSO distortions induced by $\mathrm{CH} 37$ and $\mathrm{CH} 62$ are located at $\mathrm{CH} 19(151.25 \mathrm{MHz}-$ $150 \mathrm{MHz}=1.25 \mathrm{MHz})$ and $\mathrm{CH} 117(752.5 \mathrm{MHz}-751.25 \mathrm{MHz}=1.25 \mathrm{MHz})$. The above results tell us that $\mathrm{CSO}$ distortions induced by $\mathrm{CH} 37$ and $\mathrm{CH} 62$ are located at the unused channels of $\mathrm{CH} 19$ and $\mathrm{CH} 117$, by which far from the carrier frequencies of $\mathrm{CH} 37$ and CH62. By using two-channel transmission scheme, system II can dramatically remove a major part of CSO distortions. Similarly, we can also derive the third-order intermodulation distortions (IMD3):

$$
\begin{aligned}
& 301.25 \mathrm{MHz}(\mathrm{CH} 37) * 2-451.25 \mathrm{MHz}(\mathrm{CH} 62)=151.25 \mathrm{MHz} \\
& 451.25 \mathrm{MHz}(\mathrm{CH} 62) * 2-301.25 \mathrm{MHz}(\mathrm{CH} 37)=601.25 \mathrm{MHz}
\end{aligned}
$$

The carrier frequencies of $\mathrm{CH} 19$ and $\mathrm{CH} 87$ are 151.25 and $601.25 \mathrm{MHz}$, it also can be seen that the CTB distortions induced by $\mathrm{CH} 37$ and $\mathrm{CH} 62$ are located at $\mathrm{CH} 19$ and $\mathrm{CH} 87$. The above results tell us that CTB distortions induced by $\mathrm{CH} 37$ and $\mathrm{CH} 62$ are located at the unused channels of $\mathrm{CH} 19$ and $\mathrm{CH} 87$, by which far from the carrier frequencies of $\mathrm{CH} 37$ and CH62. By using two-channel transmission scheme, system II can dramatically remove a major part of CTB distortions.

\section{Conclusions}

In this paper, we presented a fiber optical cable television (CATV) transport system using Fabry-Perot laser diodes (FP LDs) with split band technique. Unlike conventional full channel transmission, the 77-channel NTSC system selects only two channels using two converters at each moment, indicating a two-channel form transmission. For the two-channel form with split band technique transmission system, both IMD2 and IMD3 distortions are located in the unused frequency band. Distortion-induced interferences can be obviously suppressed. The values of both CSO and CTB for two-channel transmission are much higher than those of conventional full channel transmission. The value of CNR for the proposed system is less by about $2 \mathrm{~dB}$ than that of the conventional system because the direct modulation scheme has insufficient amplifier output power and less power in receiver. In addition, the performance of this system can be improved further using a push-pull preamplifier circuit that eliminates other high-order harmonic distortions to obtain excellent CSO and CTB values. The proposed system can instead of requiring the use of externally modulated 1550-nm transmitter, sophisticated SBS suppression, and differential detection techniques, only uses a high-power FP laser diode to transmit signals over $40 \mathrm{~km}$ with good performance in terms of CNR $(\geq 50 \mathrm{~dB})$, CSO $(\geq 70 \mathrm{~dB})$ and CTB ( $\geq 72 \mathrm{~dB}$ ). Compared to externally modulated $1550-\mathrm{nm}$ transmission systems, our proposed system has the distinctive advantages of simplicity and cost effectiveness, and is very suitable to local village and town communications.

\section{References}

1. W.S. Tsai, H.L. Ma, H.H. Lu, Y.P. Lin, H.Y. Chen, S.C. Yan, Opt. Exp. 18, 26077-26083 (2010)

2. W.Y. Lin, C.H. Chang, P.C. Peng, H.H. Lu, and C.H. Huang, Opt. Exp. 10, 10301-10307 (2010)

3. H.S. Su, C.Y. Li, W.Y. Lin, H.H. Lu, C.H. Chang, P.Y. Wu, Y.P. Lin, C.Y. Chen, Opt. Exp. 19, 26928-26935 (2011) 
4. H.H. Lu, A.S. Patra, S.J. Tzeng, H.C. Peng, W.I. Lin, IEEE Photon. Technol. Lett. 20, 351-353 (2008)

5. C.Y. Li, H.S. Su, C.Y. Chen, H.H. Lu, H.W. Chen, C.H. Chang, C.H. Jiang, Opt. Exp. 19, 14000-14007 (2011)

6. W.H. Chen, and W.I. Way, IEEE/OSA J Lightw. Technol. 22, 1679-1693 (2004)

7. H.H. Lu, IEEE Photon. Technol. Lett. 14, 1478-1480 (2002)

8. M.R. Phillips, K.Y. Wu, and F.X. Villarruel, IEEE/OSA J Lightw. Technol. 26, 2647-2652 (2008)

9. C.H. Yeh, C.W. Chow, Y.F. Wu, F.Y. Shih, J.H. Chen, and C.L. Pan, IEEE Photon. Technol. Lett. 23, 1627-1629 (2011)

10. P.Y. Wu, H.H. Lu, C.L. Ying, C.Y. Li, and H.S. Su, IEEE/OSA J Lightw. Technol. 29, 2422-2427 (2011)

11. W.I. Way, Broadband Hybrid Fiber/Coax Access System Technologies (New York: Academic, 1998)

12. S. Ovadia, Advances in red VCSEL technology, Broadband Cable TV Access Networks: Form Technologies to Application s ( Prentice-Hall, 2001) 